\title{
Rapid Analysis of Multiresidual Pesticides in Agricultural Products by Gas Chromatography-mass Spectrometry
}

\author{
Liu Libin ${ }^{1}$, Yuki Hashi ${ }^{2, *}$, Qin Yaping ${ }^{2}$, Zhou Haixia ${ }^{2}$, Lin Jinming ${ }^{1, *}$ \\ ${ }^{1}$ State Key Laboratory of Environmental Chemistry and Ecotoxicology, Research Center for Eco-Environmental Sciences, Chinese Academy \\ of Sciences, Beijing 100085, China \\ ${ }^{2}$ Shimadzu (Hong Kong) Limited, Beijing Office, Analytical Applications Center, Life Tower, Chao Yang District, Beijing 100020, China
}

\begin{abstract}
A method for the rapid analysis of multiresidual pesticides in agricultural products using gas chromatography-mass spectrometry (GC/MS) was introduced. The matrix solid-phase dispersion (MSPD) technique with slight modification was employed to minimize the matrix interferences. To calculate the recovery, 97 target pesticides were spiked into a range of foods including potato, cabbage, carrot, apple, orange, cucumber, and rice. The combination of the MSPD technique and the GC/MS for the analysis of 97 pesticides can be accomplished within 90 min for each sample. Most pesticides were recovered in the range of $70 \%-120 \%$ with relative standard deviation (RSD) usually less than $10 \%$. The results demonstrated that the method could be successfully applied to a broad range of target pesticides in a diverse range of foods.
\end{abstract}

Key Words: Gas chromatography-mass spectrometry; Agricultural products; Residual pesticides

\section{Introduction}

With the increasing focus on food safety in the recent years, there is a dire need to develop analytical methods that can rapidly and exactly determine the residual pesticides in agricultural products. However, the complicated matrix of the agricultural products may affect the accuracy of the analysis. Hence, the pretreatment before the analysis is very important $t^{[1,2]}$. Although many pretreatment methods have been reported $^{[3-7]}$, they are time-consuming.

To resolve the problems mentioned above and to obtain the veracity and accuracy, GC/MS was used in many groups to determine the residual pesticides in agricultural products ${ }^{[8-11]}$. Ninety-seven pesticides were studied in this work including organophosphorus, organochlorine, organonitrogen, carbamate, and thiocarbamate substances, which were spiked into seven kinds of agricultural products at the $100 \mathrm{ng} \mathrm{ml}^{-1}$ level. The samples were cleaned using the slightly modified MSPD technique and were analyzed using $\mathrm{GC}$ or $\mathrm{GC} / \mathrm{MS}^{[12,13]}$. The combination of the MSPD technique and the GC/MS realized the rapid determination of the 97 pesticides with acceptable recoveries.

\section{Experimental}

\subsection{Instrument and reagents}

Acetone and acetonitrile (chromatographic grade) were obtained from Tedia Company, Inc., USA. Water was freshly deionized using a Milli-Q water purification system with a $0.22-\mu \mathrm{m}$ fiber filter.

The analytical-grade sodium chloride was obtained from the Beijing Chemical Factory, China. Anhydrous magnesium sulfate was obtained from Kanto Chemical Co. Inc., Tokyo, Japan. Primary secondary amine (PSA) sorbent (Bond Elut PSA) was obtained from Varian (Harbor City, CA, USA).

Two groups of stock standard solutions of pesticides were obtained from Kanto Chemical Co. Inc., Tokyo, Japan. One

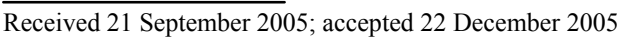

* Corresponding author. Email: jmlin@mail.rcees.ac.cn or y-hashi@shimadzu.co.jp; Tel: +86 10-62841953; Fax: +86 10-62841953

This work was supported by the National Natural Science Foundation of China (No.20437020) and the Major Research Program of Chinese Academy of Sciences (No.KZCX3-SW-432) 
group contained 50 pesticides and the other contained 47 pesticides, both being dissolved in acetone. The concentrations of the two groups of stock standard solutions were $10 \mu \mathrm{g} \mathrm{ml}^{-1}$, and the solutions were stored at $-25{ }^{\circ} \mathrm{C}$. Before each experiment, the solution containing the 97 pesticides for analysis was prepared by mixing the two groups of stock standard solutions and was diluted into the desired concentration using acetone.

The GC/MS-QP2010 used in this study was obtained from Shimadzu Company (Kyoto, Japan). An RTX-5ms column ((5\% phenyl) methylpolysiloxane; $0.25 \mathrm{~mm}$ i.d. $\times 30 \mathrm{~m}$ with a film thickness of $0.25 \mu \mathrm{m}$; Restek Corporation, Bellefonte, PA, USA) was used for the separation of the pesticides. The temperature of the capillary column was set at $80{ }^{\circ} \mathrm{C}$ for the initial $2 \mathrm{~min}$, which was increased to $180{ }^{\circ} \mathrm{C}$ at $20^{\circ} \mathrm{C} \mathrm{min}^{-1}$ and then to $280^{\circ} \mathrm{C}$ at $5^{\circ} \mathrm{C} \mathrm{min}^{-1}$ for $20 \mathrm{~min}$. Helium was used as the carrier gas. The quadrupole mass spectrometer was operated in the electron impact ion (EI) mode with a source temperature of $230^{\circ} \mathrm{C}$ and an electron energy of $70 \mathrm{eV}$.

\subsection{Sample preparation}

All samples were purchased from local markets in Beijing, China. The samples were extensively crushed to achieve good sample homogeneity. After crushing, in the case of rice, an extra step of filtering through a sifter $(0.45 \mathrm{~mm}$ aperture $)$ was required. Once homogenized, the samples were stored at -25 ${ }^{\circ} \mathrm{C}$ until GC/MS analysis was carried out.

To prepare the samples, $10 \mathrm{~g}$ of a previously homogenized food material was transferred into a suitable glass vessel (for rice, an extra $10 \mathrm{ml}$ of deionized water was added). Ten milliliters acetonitrile was then added to each sample using an adjustable-volume solvent dispenser. The glass vessels were capped before mixing on Vortex mixer for $1 \mathrm{~min}$ at optimum speed. Once the initial sample mixing was completed, $1 \mathrm{~g}$ $\mathrm{NaCl}$ and $4 \mathrm{~g}$ anhydrous $\mathrm{MgSO}_{4}$ were added and immediately mixed on a Vortex mixer for $1 \mathrm{~min}$.

To separate the phases, the samples were centrifuged for 10 $\min$ at $3000 \mathrm{rpm}$. Using an adjustable repeating pipette, $1.0 \mathrm{ml}$ aliquot of upper acetonitrile layer was transferred into a 1.5-ml flip-top microcentrifuge vial containing $150 \mathrm{mg}$ anhydrous $\mathrm{MgSO}_{4}$ and $50 \mathrm{mg}$ PSA sorbent. The vial was tightly capped and shaken on a Vortex mixer for $1 \mathrm{~min}$ before the extracts (or the batch of extracts) were centrifuged (Wealtec, e-centrifuge) for $5 \mathrm{~min}$ to separate the solids from the solution. The solution was then transferred into an autosampler vial for GC/MS analysis. For spiked samples, standard pesticides were spiked into the samples before adding acetonitrile for extraction; the other steps were the same as described above.

\section{Results and discussion}

\subsection{The chromatogram of mixed standard pesticides}

The chromatogram of the 97 standard pesticides $(500 \mathrm{ng} / \mathrm{ml})$ is shown in Fig. 1. It is seen that the total analysis time for the 97 pesticides in GC/MS was $50 \mathrm{~min}$, whereas $40 \mathrm{~min}$ was sufficient for the pretreatment of each sample. Table 1 shows the retention time and the quantification ions of 10 representative pesticides including organophosphorus, organochlorine, organonitrogen, carbamate, and thiocarbamate substances.

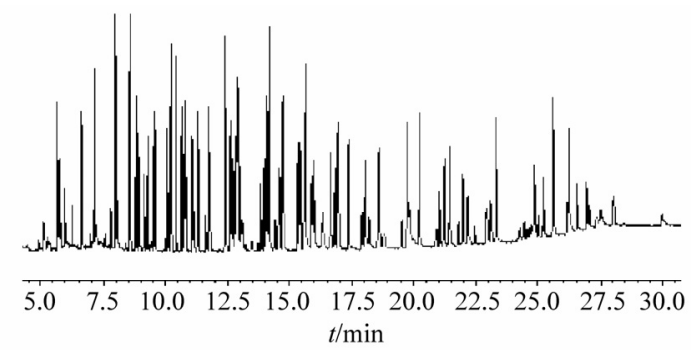

Fig. 1 Chromatogram of 97 standard pesticides (500 ng ml$^{-1}$ )

\subsection{Calibration curve and detection limit}

Three standard solutions of all the standard pesticides (50, 100 , and $500 \mathrm{ng} \mathrm{ml}^{-1}$ ) were determined for the calibration curves. Each calibration point was obtained based on three duplicate injections of the standard sample. Because the absorption phenomena may occur at a low concentration of the pesticide compounds, a second order of the calibration curve was employed. The regression equations and the correlation coefficients of the representative pesticides are also shown in Table 1.

It is seen that in this study, the second-order regression equations fitted the calibration data better than the conventional linear equations. The estimated limits of detection (LOD) and quantitation (LOQ) calculated as the concentration that produced a signal equal to 3 times and 10 times the background noise level, for the three analyzed matrices: potato, apple, and rice were obtained, which are listed in Table 2.

\subsection{Recovery test}

Recovery of the 97 pesticides $\left(100 \mathrm{ng} \mathrm{ml}^{-1}\right)$ spiked into potato, cabbage, carrot, apple, orange, cucumber, and rice was investigated using GC/MS. The chromatogram of the pesticides spiked into rice, apple, and cabbage is shown in Fig. 2. To calculate the recovery, the spiked sample from each agricultural product was prepared thrice, and the unspiked samples were also investigated. Some of the average recovery results and the relative standard deviations (RSD) are shown in Table 3. Most pesticides were recovered within an acceptable recovery range of $70 \%-120 \%$. The reasons for some higher or lower recoveries may be due to some 
interferences that remained in the matrix, or some unstable compounds that decomposed in the extraction step or in the analysis process. In addition, more pesticides in vegetables and fruits showed acceptable recoveries than those in rice because of the more complicated matrix of rice. On the whole, the MSPD technique reduced the interferences of the matrix to a large degree and could be applied to a more complicated matrix such as rice. Furthermore, the low RSD values (usually $<10 \%$ ) indicated the high reproducibility of the system.

Table 1 Regression data, retention times, and quantification ions of the representative pesticides

\begin{tabular}{|c|c|c|c|c|c|c|}
\hline \multirow[t]{2}{*}{ Pesticides } & \multirow{2}{*}{$\begin{array}{l}\text { Retention } \\
\text { time (min) }\end{array}$} & \multirow{2}{*}{$\begin{array}{c}\text { Quantification } \\
\text { ion }(m / z)\end{array}$} & \multicolumn{3}{|c|}{$y=\mathrm{a} x^{2}+\mathrm{b} x+\mathrm{c}$} & \multirow[t]{2}{*}{$r$} \\
\hline & & & $\mathrm{a}$ & $\mathrm{b}$ & $\mathrm{c}$ & \\
\hline Eptam & 6.600 & 128 & -0.3215222 & 5173.438 & -37879.61 & 0.9998 \\
\hline Butylate & 7.118 & 156 & 0.383311 & 3158.303 & -6202.944 & 0.9998 \\
\hline $\begin{array}{l}\alpha \text {-Benzene } \\
\text { hexachloride }\end{array}$ & 9.535 & 219 & 0.470097 & 1181.535 & -58.5139 & 0.9998 \\
\hline $\begin{array}{l}\delta \text {-Benzene } \\
\text { hexachloride }\end{array}$ & 10.741 & 219 & 0.456664 & 705.060 & 1728.819 & 0.9997 \\
\hline Carbaryl & 11.823 & 144 & 3.60645 & 1112.737 & -46132.75 & 0.9988 \\
\hline Diethofencarb & 12.682 & 267 & 1.004072 & 858.599 & -14990.14 & 0.9995 \\
\hline Fenthion & 12.850 & 278 & 2.969206 & 3138.779 & -7438.472 & 0.9996 \\
\hline Chlorpyrifos & 12.896 & 197 & 0.944697 & 886.365 & 2237.986 & 0.9996 \\
\hline Tebufenpyrad & 20.243 & 318 & 1.659283 & 1403.177 & -683.083 & 0.9995 \\
\hline Pyridaben & 23.307 & 147 & 13.40633 & 5326.545 & 59432.15 & 0.9990 \\
\hline
\end{tabular}

$y$ and $x$ indicate the peak area and the concentration $(\mathrm{ng} / \mathrm{ml})$ of the pesticides, respectively. The correlation coefficients are expressed as $r$

Table 2 Estimated limits of detection (LOD) and quantitation (LOQ) calculated as the concentration that produced a signal equal to 3 times and 10 times the background noise level

\begin{tabular}{lcccccc}
\hline Pesticides & \multicolumn{3}{c}{ LOD $(\mathrm{ng} / \mathrm{g})$} & \multicolumn{3}{c}{ LOQ $(\mathrm{ng} / \mathrm{g})$} \\
\cline { 2 - 7 } & Potato & Apple & Rice & Potato & Apple & Rice \\
\hline Eptam & 15 & 56 & 90 & 50 & 186 & 297 \\
Butylate & 65 & 47 & 52 & 216 & 156 & 173 \\
$\alpha$-Benzene hexachloride & 58 & 14 & 23 & 193 & 47 & 77 \\
$\delta$ - Benzene hexachloride & 52 & 30 & 71 & 173 & 100 & 236 \\
Carbaryl & 27 & 54 & 47 & 90 & 180 & 156 \\
Diethofencarb & 26 & 26 & 30 & 86 & 86 & 100 \\
Fenthion & 8 & 6 & 7 & 27 & 20 & 23 \\
Chlorpyrifos & 25 & 32 & 33 & 83 & 107 & 110 \\
Tebufenpyrad & 12 & 9 & 22 & 40 & 30 & 73 \\
Pyridaben & 12 & 11 & 10 & 40 & 37 & 33 \\
\hline
\end{tabular}

Table 3 Results of the recovery test

\begin{tabular}{|c|c|c|c|c|c|c|c|c|c|c|c|c|c|c|c|}
\hline & \multirow[b]{2}{*}{ Pesticides } & \multicolumn{2}{|c|}{ Potato } & \multicolumn{2}{|c|}{ Cabbage } & \multicolumn{2}{|c|}{ Carrot } & \multicolumn{2}{|c|}{ Cucumber } & \multicolumn{2}{|c|}{ Apple } & \multicolumn{2}{|c|}{ Orange } & \multicolumn{2}{|c|}{ Rice } \\
\hline & & $\begin{array}{c}\text { Mean } \\
(\%)\end{array}$ & $\begin{array}{l}\text { RSD } \\
(\%)\end{array}$ & $\begin{array}{c}\text { Mean } \\
(\%)\end{array}$ & $\begin{array}{l}\text { RSD } \\
(\%)\end{array}$ & $\begin{array}{c}\text { Mean } \\
(\%)\end{array}$ & $\begin{array}{l}\text { RSD } \\
(\%)\end{array}$ & $\begin{array}{c}\text { Mean } \\
(\%)\end{array}$ & $\begin{array}{l}\text { RSD } \\
(\%)\end{array}$ & $\begin{array}{c}\text { Mean } \\
(\%)\end{array}$ & $\begin{array}{l}\text { RSD } \\
(\%)\end{array}$ & $\begin{array}{c}\text { Mean } \\
(\%)\end{array}$ & $\begin{array}{l}\text { RSD } \\
(\%)\end{array}$ & $\begin{array}{c}\text { Mean } \\
(\%)\end{array}$ & $\begin{array}{l}\text { RSD } \\
(\%)\end{array}$ \\
\hline 1 & (Z)-Dimethylvinphos & 94 & 2.3 & 99 & 1.7 & 97 & 6.7 & 112 & 7.6 & 116 & 4.0 & 164 & 4.4 & 116 & 4.4 \\
\hline 2 & Acephate & 194 & 5.1 & 205 & 1.6 & 220 & 6.4 & 75 & 27.8 & 116 & 4.3 & 108 & 1.4 & 108 & 4.7 \\
\hline 3 & Acetamiprid & 89 & 2.9 & 100 & 3.0 & 108 & 3.3 & 106 & 6.4 & 88 & 1.7 & 101 & 5.0 & 198 & 1.0 \\
\hline 4 & Acrinathrin & 85 & 4.6 & 113 & 3.1 & 88 & 8.8 & 104 & 6.5 & 116 & 1.7 & 120 & 5.3 & 114 & 4.2 \\
\hline 5 & Bendiocarb & 71 & 4.3 & 94 & 4.3 & 75 & 7.6 & 97 & 2.9 & 107 & 6.4 & 165 & 5.4 & 111 & 4.7 \\
\hline 6 & Benfuresate & 75 & 2.2 & 77 & 1.9 & 77 & 3.7 & 71 & 3.5 & 78 & 4.9 & 114 & 6.6 & 87 & 6.7 \\
\hline 7 & Bitertanol & 95 & 3.1 & 91 & 5.8 & 114 & 1.1 & 189 & 9.3 & 115 & 4.0 & 130 & 1.3 & 199 & 3.4 \\
\hline 8 & Fenobucarb & 79 & 1.4 & 86 & 1.5 & 74 & 5.3 & 93 & 3.7 & 79 & 1.0 & 119 & 1.0 & 83 & 8.4 \\
\hline 9 & Butylate & 68 & 1.9 & 69 & 2.4 & 69 & 0.6 & 64 & 2.5 & 57 & 5.8 & 93 & 2.8 & 60 & 7.2 \\
\hline 10 & Cadusafos & 74 & 0.9 & 77 & 1.2 & 80 & 1.2 & 92 & 3.3 & 81 & 4.0 & 97 & 3.1 & 84 & 4.3 \\
\hline
\end{tabular}




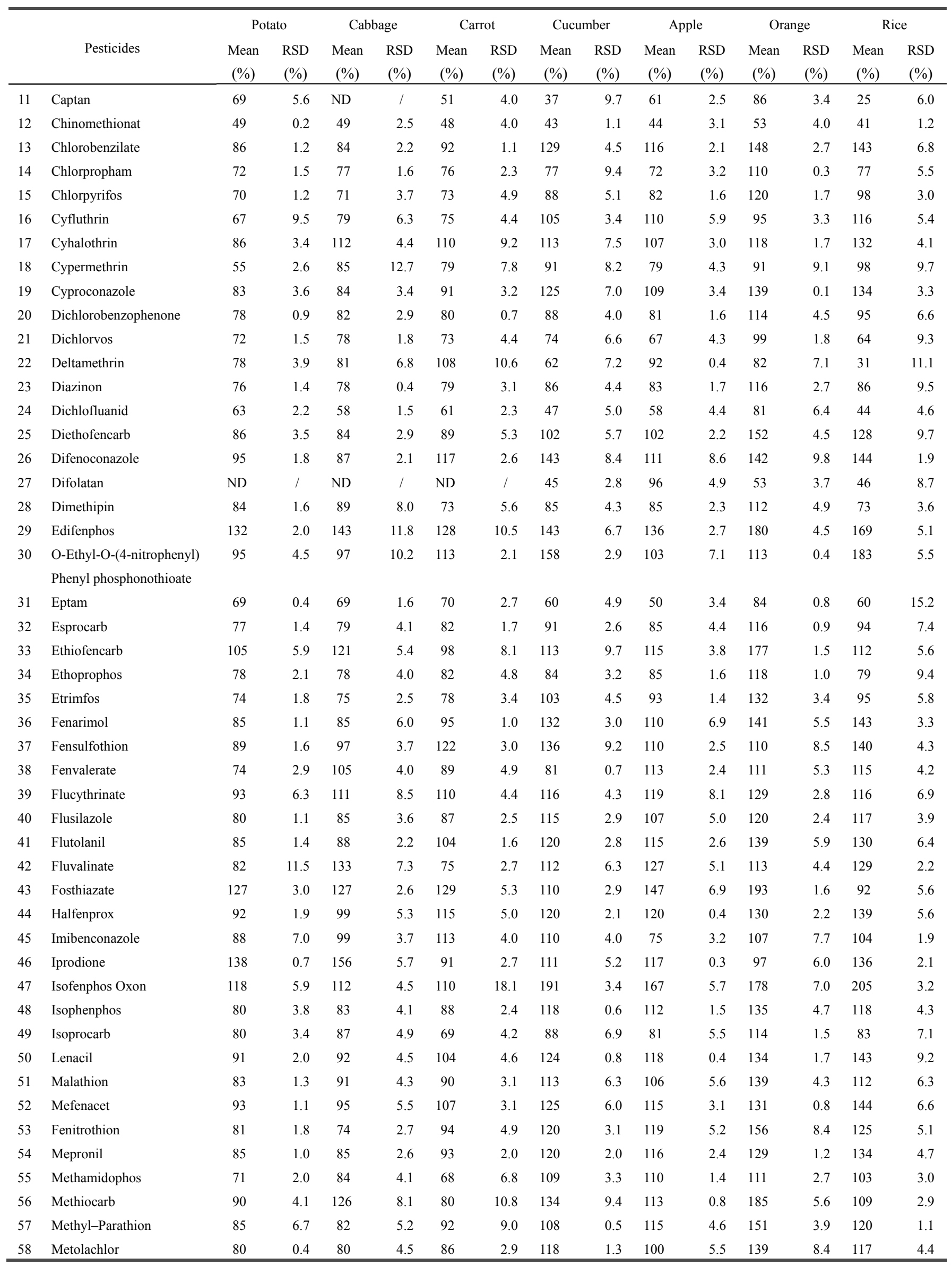




\begin{tabular}{|c|c|c|c|c|c|c|c|c|c|c|c|c|c|c|c|}
\hline & \multirow[b]{2}{*}{ Pesticides } & \multicolumn{2}{|c|}{ Potato } & \multicolumn{2}{|c|}{ Cabbage } & \multicolumn{2}{|c|}{ Carrot } & \multicolumn{2}{|c|}{ Cucumber } & \multicolumn{2}{|c|}{ Apple } & \multicolumn{2}{|c|}{ Orange } & \multicolumn{2}{|c|}{ Rice } \\
\hline & & $\begin{array}{l}\text { Mean } \\
(\%)\end{array}$ & $\begin{array}{l}\text { RSD } \\
(\%)\end{array}$ & $\begin{array}{c}\text { Mean } \\
(\%)\end{array}$ & $\begin{array}{l}\text { RSD } \\
(\%)\end{array}$ & $\begin{array}{l}\text { Mean } \\
(\%)\end{array}$ & $\begin{array}{l}\text { RSD } \\
(\%)\end{array}$ & $\begin{array}{c}\text { Mean } \\
(\%)\end{array}$ & $\begin{array}{l}\mathrm{RSD} \\
(\%)\end{array}$ & $\begin{array}{l}\text { Mean } \\
(\%)\end{array}$ & $\begin{array}{l}\text { RSD } \\
(\%)\end{array}$ & $\begin{array}{c}\text { Mean } \\
(\%)\end{array}$ & $\begin{array}{l}\text { RSD } \\
(\%)\end{array}$ & $\begin{array}{c}\text { Mean } \\
(\%)\end{array}$ & $\begin{array}{l}\mathrm{RSD} \\
(\%)\end{array}$ \\
\hline 59 & Fenthion & 76 & 1.4 & 81 & 1.6 & 83 & 1.8 & 95 & 6.1 & 89 & 4.8 & 112 & 0.8 & 88 & 7.9 \\
\hline 60 & Myclobutanil & 84 & 1.8 & 84 & 1.9 & 93 & 2.7 & 110 & 7.7 & 111 & 1.4 & 112 & 6.0 & 128 & 8.4 \\
\hline 61 & Carbaryl & 78 & 4.8 & 124 & 12.3 & 78 & 11.7 & 115 & 2.4 & 120 & 3.0 & 146 & 6.6 & 111 & 5.5 \\
\hline 63 & $\begin{array}{l}p, p^{\prime} \text {-Dichloro- } \\
\text { diphenyldichloroethylene }\end{array}$ & 82 & 3.0 & 82 & 3.3 & 81 & 1.3 & 85 & 5.0 & 80 & 5.1 & 115 & 4.1 & 87 & 6.0 \\
\hline 64 & Paclobutrazol & 84 & 2.2 & 83 & 4.8 & 92 & 1.7 & 118 & 4.4 & 110 & 6.3 & 150 & 4.8 & 81 & 3.2 \\
\hline 65 & Phenthoate & 78 & 2.5 & 80 & 3.5 & 89 & 4.8 & 111 & 7.6 & 103 & 7.4 & 135 & 5.8 & 114 & 5.8 \\
\hline 66 & Parathion & 83 & 1.1 & 77 & 9.5 & 96 & 9.4 & 136 & 9.4 & 118 & 1.9 & 158 & 6.1 & 135 & 1.0 \\
\hline 67 & Pendimethalin & 85 & 4.5 & 79 & 2.9 & 96 & 7.1 & 129 & 5.1 & 114 & 0.6 & 154 & 4.2 & 138 & 8.7 \\
\hline 68 & Permethrin & 92 & 1.6 & 95 & 2.9 & 98 & 3.5 & 108 & 6.3 & 112 & 2.2 & 109 & 0.0 & 119 & 0.7 \\
\hline 69 & Phosalone & 87 & 0.9 & 95 & 5.9 & 103 & 8.9 & 131 & 9.4 & 115 & 4.2 & 97 & 1.2 & 151 & 4.6 \\
\hline 70 & Pirimicarb & 76 & 1.4 & 78 & 2.0 & 80 & 1.5 & 82 & 5.8 & 79 & 1.9 & 114 & 0.1 & 89 & 5.7 \\
\hline 71 & Pirimiphos-methyl & 76 & 1.2 & 82 & 2.9 & 84 & 2.2 & 103 & 5.7 & 98 & 7.1 & 131 & 2.9 & 112 & 5.1 \\
\hline 72 & Pretilachlor & 88 & 1.3 & 83 & 2.7 & 101 & 4.3 & 134 & 3.6 & 120 & 1.3 & 164 & 4.9 & 146 & 6.1 \\
\hline 73 & Propiconazole & 85 & 3.6 & 86 & 1.1 & 92 & 1.8 & 143 & 0.4 & 113 & 3.4 & 115 & 2.3 & 136 & 8.9 \\
\hline 74 & Prothiofos & 80 & 2.1 & 83 & 4.8 & 85 & 1.6 & 104 & 6.8 & 97 & 3.9 & 130 & 6.1 & 114 & 7.3 \\
\hline 75 & Pyraclofos & 141 & 4.2 & 157 & 5.1 & 161 & 14.6 & 164 & 8.6 & 151 & 7.0 & 185 & 1.7 & 199 & 8.4 \\
\hline 76 & Pyridaben & 89 & 0.4 & 96 & 2.6 & 103 & 3.8 & 116 & 1.8 & 117 & 1.3 & 113 & 1.5 & 130 & 4.5 \\
\hline 77 & Pyrifenox & 79 & 0.4 & 81 & 3.5 & 85 & 3.6 & 119 & 1.4 & 100 & 0.7 & 138 & 4.1 & 130 & 5.5 \\
\hline 78 & Pyrimidifen & 94 & 1.2 & 101 & 3.9 & 107 & 0.8 & 120 & 1.3 & 125 & 2.6 & 138 & 4.8 & 132 & 3.6 \\
\hline 81 & Silafluofen & 90 & 0.4 & 92 & 0.4 & 92 & 1.0 & 119 & 2.4 & 115 & 1.3 & 120 & 0.9 & 128 & 7.1 \\
\hline 82 & Tebuconazole & 82 & 1.0 & 84 & 2.0 & 93 & 1.1 & 132 & 1.8 & 111 & 3.3 & 133 & 5.5 & 136 & 1.2 \\
\hline 83 & Tebufenpyrad & 89 & 2.6 & 91 & 2.2 & 92 & 4.8 & 114 & 3.3 & 111 & 2.5 & 129 & 4.8 & 130 & 8.6 \\
\hline 84 & Tefluthrin & 76 & 0.9 & 79 & 1.6 & 80 & 2.3 & 86 & 5.0 & 78 & 1.4 & 114 & 4.4 & 79 & 8.1 \\
\hline 85 & Terbufos & 75 & 2.9 & 78 & 3.7 & 81 & 2.9 & 111 & 3.9 & 101 & 2.9 & 129 & 0.3 & 108 & 3.9 \\
\hline 86 & Thenylchlor & 88 & 1.6 & 85 & 3.6 & 98 & 3.6 & 117 & 3.2 & 95 & 3.0 & 119 & 1.4 & 129 & 6.5 \\
\hline 87 & Thiobencarb & 77 & 1.9 & 78 & 1.6 & 81 & 1.6 & 95 & 4.1 & 75 & 2.6 & 105 & 2.4 & 86 & 8.8 \\
\hline 88 & Thiometon & 74 & 2.6 & 75 & 2.2 & 79 & 2.7 & 93 & 2.7 & 84 & 2.1 & 120 & 1.9 & 88 & 7.8 \\
\hline 89 & Tolclofos-methyl & 76 & 1.4 & 80 & 1.9 & 82 & 0.9 & 91 & 7.7 & 84 & 2.6 & 118 & 2.2 & 88 & 5.7 \\
\hline 90 & Triadimenol & 79 & 4.8 & 82 & 5.6 & 91 & 2.2 & 86 & 6.1 & 114 & 2.1 & 116 & 3.0 & 117 & 8.4 \\
\hline 91 & Tricyclazole & 94 & 3.3 & 100 & 2.2 & 111 & 2.3 & 110 & 5.9 & 84 & 8.7 & 92 & 4.6 & 108 & 2.9 \\
\hline 92 & $\alpha$-Benzene hexachloride & 76 & 2.4 & 79 & 1.0 & 79 & 1.7 & 73 & 2.4 & 56 & 1.3 & 107 & 0.1 & 69 & 8.8 \\
\hline 93 & $\alpha$-Chlorfenvinphos & 91 & 3.5 & 95 & 1.3 & 94 & 3.8 & 119 & 0.7 & 116 & 2.5 & 160 & 6.8 & 117 & 2.6 \\
\hline 94 & $\beta$-Benzene hexachloride & 80 & 3.4 & 83 & 6.6 & 83 & 4.5 & 90 & 4.3 & 99 & 2.5 & 113 & 3.3 & 89 & 7.9 \\
\hline 95 & $\beta$-Chlorfenvinphos & 91 & 3.5 & 95 & 1.3 & 94 & 3.9 & 119 & 0.7 & 119 & 2.0 & 153 & 3.2 & 130 & 9.4 \\
\hline 96 & $\gamma$-Benzene hexachloride & 76 & 0.9 & 77 & 4.5 & 76 & 5.2 & 84 & 1.4 & 63 & 4.7 & 114 & 0.7 & 72 & 2.8 \\
\hline 97 & $\delta$-Benzene hexachloride & 66 & 6.4 & 82 & 2.6 & 75 & 4.6 & 68 & 13.7 & 53 & 5.7 & 76 & 4.2 & 56 & 8.8 \\
\hline
\end{tabular}

Mean: average recovery; RSD: relative standard deviation; ND: not detected

\section{Conclusions}

The GC/MS system for the analysis of multiresidual pesticides in agricultural products was developed in this study. This article also provides some references for the analysis of residual pesticides in some other products. The MSPD technique reduced the interferences of the matrix to some degree. The results showed that most pesticides were recovered within an acceptable recovery range of $70 \%-120 \%$ and the RSD values were usually less than $10 \%$. The method can be successfully applied to accurately and rapidly analyze a broad range of target pesticides in a diverse range of foods. 
This may become a routine method for determining residual pesticides in products.

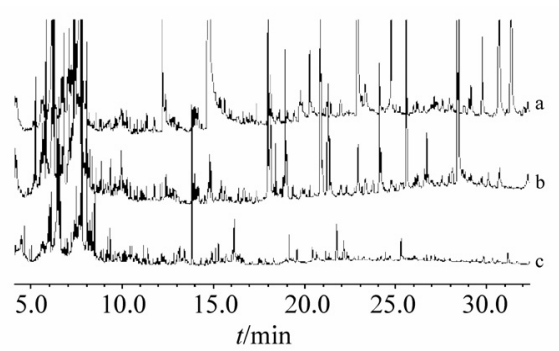

Fig. 2 Chromatogram of pesticides spiked into rice (a), apple (b) and cabbage (c)

\section{References}

[1] Zambonin C G, Quinto M, Vietro N D, Palmisano F, Food Chemistry, 2004, 86: 269-274

[2] Albero B, Brunete C S, Tadeo J L, Talanta, 2005, 66: 917-924
[3] Feng S, Wang B, Qu H. Heilongjiang Agricultural Sciences, 2005, (3): 27-29

[4] Xu T, Li J, University Chemistry, 2003, 18(6): 5-11

[5] Wan Y, Yan A, Xie M. Chin. J. Anal. Chem., 2005, 33(5): 614-618

[6] Li Y, Chu X, Zhong W, Li S, He Y, Chin. J. Anal. Chem., 2004, 32(10): 1325-1328

[7] Liu Y, Wang Z, Chu X. Chin. J. Anal. Chem., 2005, 33(6): 808-810

[8] Li F, Quan X, Chin. J. Anal. Chem., 2005, 33 (6): 838-842

[9] Zhao X, Yu T, Zhu G, Lu P, Yang L, Wang S, Wang J, Chin. J. Chromatogr., 2005, 23(3): 328-328

[10] Li Y, Huang Z, Dai H, Zhang Y, Chin. J. Anal. Chem., 2002, 30(7): 865-868

[11] Zheng X, Chin. J. Anal. Chem., 2004, 32(2): 225-228

[12] Anastassiades M, Lehotay S J, Stajnbaher D, Schenck F J, $J$. AOAC Int., 2003, 86: 412-431

[13] Obana H, Akutsu K, Okihashi M, Hori S, Analyst, 2001, 126: $1529-1534$ 